\title{
É POSSÍVEL EDUCAR AS EMOÇõES?
}

\author{
Is it Possible to Educate Emotions?
}

Juliana Santana de Almeida ${ }^{1}$

\begin{abstract}
RESUMO: $O$ artigo trata a possibilidade de educar as emoções existente graças à sua possibilidade de ouvir e obedecer à razão. O estudo é feito a partir das propostas da Ética a Nicômaco, recorrendo, quando necessário, ao De anima e à Retórica, textos que dedicaram atenção às emoções. Para defender essa proposta, a investigação parte do Livro I da $E N$, que indica a possibilidade de a capacidade desiderativa ouvir e obedecer a razão. Com isso, percebemos que Aristóteles não pretende excluir os elementos não racionais da vida ética, estando mais preocupado em encontrar formas capazes de conciliar as capacidades anímicas e de sentir emoções na quantidade adequada, com as coisas certas, nos momentos convenientes, em direção a quê e a quem é adequado. Essa interpretação é possível porque o filósofo compreende a alma como algo composto, pondo as emoções, que são da alçada do desiderativo em contato com a parte racional da alma. Por isso, é necessário entender que Aristóteles propõe partes da alma que quando associadas conjugam o bom exercício de todas as capacidades anímicas humanas, levando às virtudes. Interpretação viável pela apresentação de faculdades encadeadas à parte racional que pode tocar a emoção, desde seu despertar até quando for moderada com o auxílio da razão prática.
\end{abstract}

PALAVRAS-CHAVE: Emoção; Educar; Alma; Capacidades; Ética a Nicômaco.

ABSTRACT: This paper treats the possibility of educating the emotions because they are capable to listen and obey the reason. The study is based on the proposals of the Nicomachean Ethics, resorting, when necessary, to the De Anima and the Rhetoric, texts that devoted attention to the emotions. To defend this proposal, the investigation starts from Book I of the $E N$, which indicates the possibility of desiderative ability to hear and obey to the reason. Therefore, we realize that Aristotle does not intend to exclude non-rational elements to a ethical life, but is more concerned to find ways that can reconcile soul capacities and feel emotions in the right amount, with the right things, at the right times, in direction to whom it is appropriate. This interpretation is possible because the philosopher understands the soul as something composed, putting the emotions, which belongs to the desiderative in contact with the rational part of the soul. Consequently, it is necessary to understand that Aristotle proposes that soul's parts when associated combine the proper exercise of all its capacities, allowing the virtues to exist. This interpretation is viable because the non-rational faculties can be linked to the rational part, and it can touch the emotion, from its awakening until when it is moderated with the aid of practical reason.

KEYWORDS: Emotions; To educate; Soul; Capacities; Nichomachean Ethics.

\footnotetext{
${ }^{1}$ Doutora em Filosofia pela Universidade Federal de Santa Catarina (UFSC), professora de filosofia na Universidade Federal do Tocantins (UFT). E-mail: jusantanaa@hotmail.com
} 
Na história da filosofia, o entendimento acerca do que sejam as emoções (páthē) varia. Aristóteles se viu em meio a posturas diversas sobre o assunto: antes e depois de suas teorias, apareceram fortes oposições à intervenção das emoções na vida ética ${ }^{2}$. Provavelmente esse tipo de apreciação é o motivo para as inúmeras considerações cautelosas que o filósofo faz sobre o páthos em sua proposta ética. Entretanto, Aristóteles não se mostra um pensador desfavorável à participação do emocional na vida humana feliz, mas mesmo nas teorias do filósofo grego, o tema das emoções pode causar embaraços, a começar pela tradução do termo por "emoção". Contudo, enfocaremos aqui as acepções que tocam nosso objeto de estudo, a saber, aquelas páthē da relação que aparece especialmente na Ética a Nicômaco, mas que igualmente se repete, com algumas variações, nas listas apresentadas na Retórica e no De Anima: raiva, arrojo, inveja, medo, alegria, amizade, ódio, anelo, emulação, piedade, calma, inimizade, desvergonha, amabilidade, indignação e mágoa. Esses últimos textos virão em nosso auxílio quando se apresentarem instrumentos eficazes à compreensão de algumas questões suscitadas pela Ética a Nicômaco a respeito da nossa investigação, que tratará a possibilidade de educar as emoções graças à racionalidade que têm lugar ou influência nelas.

Por conseguinte, justificamos nossa opção por começar o estudo ora apresentado em busca de uma compreensão melhor e maior daquilo que Aristóteles propõe partindo do Livro I da Ética a Nicômaco, de onde retiramos o pensamento que permeará toda a nossa pesquisa: as emoções são sofridas concomitantemente por corpo (sôma) e alma (psyché) e são educáveis por serem abertas ao que manda a razão, característica devida à constituição da alma humana. Tal entendimento permitirá também respondermos à questão norteadora do artigo: é possível educar as emoções conforme as solicitações da razão prática? A fim de responder tal questão, prosseguirmos, no primeiro momento do artigo, com a discussão apresentada em Ética a Nicômaco I 13 a respeito da alma humana e de suas capacidades. Esse estudo será necessário, pois nesse ponto da Ética a Nicômaco, Aristóteles nos apresenta uma alma bipartida que comporta as emoções em sua parte não

\footnotetext{
${ }^{2}$ Tal pensamento, afirma Sorabji (2000, p. 181, tradução nossa; cf. também p. 7 et seq.), é defendido por Crisipo, embora não por todos os estoicos. "Mas o que eu quero considerar neste capítulo é a tese muito mais radical de Crisipo de que quase todas elas devem ser erradicadas. Que razões poderia haver para tanto?". Contudo, as opiniões sobre a aceitação estoica da erradicação da emoção parecem divergir. Enquanto os manuais de História da Filosofia, como aqueles que foram escritos por Kenny (2011) e Reale (2003), parecem afirmar que todos os estoicos concordavam com a necessidade de erradicação das emoções, há estudos mais minuciosos sobre o assunto que parecem discordar dessa proposta e que trazem motivos significativos para tal discordância. Esse é o caso da tese de doutorado defendida por Santos na UNICAMP, em 2008. Com relação a esse tema, vale também conferir a proposta do próprio Sorabji, que nos apresenta entendimentos variados para o termo apáthēia trazidos pelos estoicos.
} 
racional, parte esta que, no entanto, apresenta-se como apta a ouvir e obedecer à razão, sinal da possibilidade de defesa da educabilidade das emoções, com a defesa de uma alma composta por capacidades (dýnameis) imprescindivelmente correlacionadas. Tudo isso será possível porque entenderemos, com um segundo momento do artigo, a capacidade da alma responsável pelas emoções, a desiderativa, como um todo coeso, embora composta por diferentes tipos de desejos conforme seus objetos e suas relações com a razão. Entender que a capacidade desiderativa (órexis) pode ouvir e obedecer à razão nos permitirá defender também emoções capazes de concordar com as solicitações da parte racional, ao menos em sua vertente prática. A possibilidade de educação que veremos se abrir à capacidade desiderativa como um todo indicará a possibilidade de propor emoções capazes de serem educadas conforme a razão. Concluiremos, com a perspectiva de educar a maioria das emoções, que estas podem ouvir e obedecer à razão. O que se mostra tipicamente humano, desde a constituição anímica.

\section{As emoções na Ética a Nicômaco - questões sobre a alma a partir de I 13}

A leitura da Ética a Nicômaco nos traz uma série de indagações quanto à natureza das emoções. A lista de tais questões pode começar pela afirmação, que às vezes aparece nesse texto, segundo a qual as emoções são não racionais. Por esse motivo, talvez tenhamos a impressão frequente de que o filósofo, em alguma medida, não seja favorável à intervenção das emoções nas ações consideradas boas moralmente. De acordo com a proposta de uma alma que "tem uma parte racional e uma irracional"3, as emoções têm por sede uma capacidade não racional da alma, a desiderativa, de onde viriam igualmente as suas relações com certos prazeres e dores. Tais associações com outros elementos que também não costumavam receber apreciação favorável em questões éticas parecem agravar a situação das emoções e provavelmente por isso sejam feitas afirmações que parecem colocar a emoção como algo arredio aos ditames da razão, sendo mesmo capaz de sobrepor-se a estes ${ }^{4}$. Várias assertivas que apresentam um tom de advertência quanto aos perigos de se entregar às emoções aparecem ao longo do texto.

\footnotetext{
${ }^{3}$ ARISTÓTELES. Ética a Nicômaco. Paris; Vrin, 2012, p. 88 (I 13 1102a27-28). Todas as citações da Ética a Nicômaco para o Português são traduções nossas a partir da tradução francesa citada, conferidas com o texto grego apresentado à edição bilingue de $\mathrm{M}$. Araujo e J. Marías e com a tradução apresentada no The Complete Works, listadas nas referências.

${ }^{4}$ O filósofo parece expressar postura semelhante também em Ética a Nicômaco 1106b35; 1107a1-9; 1097b35; 1098a1-17; 1168b34-35; 1169a18; 1177a12-18; 1178a6-7; etc.
} 
A primeira menção que o tratado faz ao assunto pode confirmar isso: no Livro I da Ética a Nicômaco, Aristóteles explica o motivo pelo qual os jovens não tiram bom proveito das lições sobre política: primeiro, não têm experiência dos fatos da vida, em torno dos quais giram as discussões dessa natureza; segundo, os jovens tendem a seguir suas paixões. Por isso, o estudo da ciência política lhes será vão, já que o fim que se almeja com essa matéria é a ação e não o conhecimento. Essas falhas abrangem tanto aqueles que são jovens em anos quanto os que são jovens em caráter, pois o defeito não depende da idade, mas do modo de viver e seguir cada objetivo proposto pela emoção. "A tais pessoas, como aos incontinentes, a ciência não traz proveito algum; mas, aos que desejam e agem de acordo com um princípio racional, o conhecimento desses assuntos fará grande vantagem"5 na distinção do que seja o bem. Por conseguinte, em nada nos admiraria a proposta da melhor vida possível como aquela guiada pela reta razão.

A felicidade, fim (télos) da vida humana, seria descrita como uma atividade (enérgeia), mas realizada conforme o que manda a razão. Tal atividade deve ser de acordo com o que é descrito como o que há de melhor no homem e que o diferencia dos outros animais e das plantas. Esse tipo de vida não seria possível sem as virtudes (aretai), especialmente sem a virtude ética, pois, além de ser conforme o que há de mais próprio ao homem, a razão, a vida boa eticamente e feliz seria aquela que permitiria desempenhar da melhor forma a função humana, e, segundo Aristóteles, desempenhar bem sua função é ser virtuoso.

Caso seja possível entender essa proposta como indicativo de que o homem deva ouvir sua razão a fim de possuir a mais excelente virtude e a melhor vida, precisamos ressaltar que Aristóteles nos chama atenção para que a razão deva ser o guia ou deva, ao menos, estar presente em todos os homens. Mas não convém esquecer que no Livro X o filósofo afirmará que tal possibilidade não é a mais recorrente - embora devesse ser - à vida humana comum. Os homens, em sua grande maioria, não obedecem espontaneamente à razão, mesmo sendo capazes de fazê-lo. Por isso, não tendem a uma vida de contemplação. Na maior parte das vezes, os elementos da parte não racional da alma conduzem as ações, sendo necessário, portanto, buscar moderá-los para que haja excelência dessa parte e que se viva a vida especificamente humana ${ }^{6}$.

\footnotetext{
${ }^{5}$ ARISTÓTELES. Ética a Nicômaco. Paris; Vrin, 2012, p. 42 (I 1 1095a11-15).

${ }^{6}$ Essa proposta é encontrada também em Política 1253a25-28: “Que nessas condições a cidade seja também anterior naturalmente ao indivíduo, isso é evidente: se, com efeito, o indivíduo tomado isoladamente é incapaz de bastar a si mesmo, será por relação à cidade como, nos nossos outros exemplos, as partes são em relação ao todo. Mas o homem que está na incapacidade de ser membro de uma comunidade, ou que
} 
A felicidade foi proposta em Ética a Nicômaco I 13 como atividade da alma conforme a virtude mais completa. Por isso, para compreender melhor o que seja a felicidade Aristóteles julga necessário estudar a natureza da virtude. O filósofo explica que a virtude a ser estudada é humana, como são humanos o bem e a felicidade que procura esclarecer. Por conseguinte, escreve: "Por virtude humana entendemos não a do corpo, mas da alma; e igualmente à felicidade chamamos uma atividade da alma. Mas, assim sendo, é óbvio que o político deve saber de algum modo o que diz respeito à alma" " $\mathrm{O}$ estudo da alma que um legislador buscaria empreender, no entanto, teria por finalidade tornar os cidadãos bons e entender como isso é possível, o que bastaria para o tipo de investigação ora feito.

Quando o tema é a alma humana, a Ética a Nicômaco aponta a existência de opiniões consideráveis, mesmo que não venham de Aristóteles ou de seus companheiros de estudo. Uma dessas opiniões considerada válida é a mencionada teoria que a alma apresenta uma parte racional e outra não racional. Costuma-se aceitar igualmente uma subdivisão da parte anímica não racional, propondo para ela primeiro uma capacidade vegetativa, responsável pela nutrição e pelo crescimento. Esta é presente em todos os animais vivos, adultos, embriões, lactantes, etc. A excelência de tal capacidade, por esse aspecto comum aos viventes, é pertencente a todos e não é especificamente humana. Além disso, a capacidade nutritiva ou vegetativa trabalha especialmente durante o sono, quando a maldade ou a bondade de caráter não se manifestam. Assim, tal capacidade pode ser posta de lado por ora em nossas investigações, já que na Ética a Nicômaco é tida como não participante da excelência tipicamente humana. No entanto, Aristóteles segue com o exame da parte não racional da alma e escreve:

Parece haver na alma ainda outro elemento irracional, mas que, em certo sentido, participa da razão. Com efeito, louvamos o princípio racional do homem continente e do incontinente, assim como a parte de sua alma que possui tal princípio, porquanto ela os impele na direção certa e para os melhores objetivos; mas, ao mesmo tempo, encontra-se neles um outro elemento naturalmente oposto ao princípio racional, lutando contra este e resistindo-lhe ${ }^{8}$.

Aristóteles assim nos adverte que na alma há algo que é contrário à parte racional, resistindo-lhe e fazendo-lhe frente. Isso parece nem participar da parte racional, embora no continente obedeça-a; no temperante e no bravo obedece ainda mais, "pois em tais homens ele fala, a respeito de todas as coisas, com a mesma voz que o princípio

disso não experimenta nada a necessidade porque ele se basta a si mesmo, não faz em nada parte de uma cidade, e por consequência é ou um bruto ou um deus".

${ }^{7}$ ARISTÓTELES. Ética a Nicômaco. Paris; Vrin, 2012, p. 86 (I 13 1102a16-19).

${ }^{8}$ Ibid., p. 89-90 (I 131102 b13-21). 
racional"’. Mesmo que esta capacidade pareça não participar da parte racional, os exemplos de virtudes e virtuosos dados no passo nos mostram que essa faculdade ou capacidade da parte não racional é constituída por querer (boúlēsis), apetite (epithymía) e impulso (thymós) que são desejos aptos a ouvir a racionalidade, obedecê-la e até participar dela, embora pareçam sempre fazer o contrário.

Até o momento, a interpretação feita nos permite afirmar que a parte não racional é ou parece ser dupla. Isso porque a vegetativa não participa da parte racional, mas a desiderativa em geral participa, ao menos de certo modo, porque, no mínimo, é capaz de escutar e obedecer à razão, como um filho ouve e obedece a um pai. Conselhos, censuras e exortações comprovam, portanto, que o não racional é, de certo modo, persuadido pela razão. O argumento/exemplo do filho e do pai dá azo ao nosso argumento, porque o filho pode ainda não possuir plenamente a razão em ato, mas é considerado, na Política, como parte da família cujo elemento racional é figurado pelo pai, sendo este representante da razão prática na analogia apresentada na Ética a Nicômaco. Essa participação, enquanto não se atualiza a potência de razão do filho, é símbolo da participação do que na alma há de menos racional, mas capaz de ouvir à razão prática. Por isso, a virtude recebe distinção semelhante nesse tratado, indicando a existência de uma virtude moral e de uma virtude intelectual, cada destas uma componente indispensável de uma alma humana que só pode ver atualizadas suas múltiplas capacidades pelo composto corpo/alma. No entanto, quando se fala do caráter humano está-se a falar da virtude ética, entendida por Aristóteles como disposição digna de louvor. Quando o agente se comporta bem diante dos arroubos de suas emoções resulta em certa felicidade numa vida em comunidade:

[...] em grau secundário, a vida de acordo com a outra espécie de virtude é feliz, porque as atividades que concordam com esta condizem com a nossa condição humana. Os atos corajosos e justos, bem como outros atos virtuosos, nós os praticamos em relação uns aos outros, observando nossos respectivos deveres no tocante a contratos, serviços e toda sorte de ações, bem assim como às paixões; e todas essas coisas parecem ser tipicamente humanas. Dir-se-ia até que algumas delas provêm do próprio corpo e que o caráter virtuoso se prende por muitos laços às paixões ${ }^{10}$.

A vida voltada aos assuntos da pólis é, portanto, feliz, mas cercada pelas inevitáveis emoções e pelos desejos. Por isso devemos dar atenção à ressalva seguinte feita por Sorabji:

Aristóteles [...] aborda a questão: será que é errado, uma vez que somos humanos, aspirar a vida mais divina de contemplação intelectual? Ele responde (embora eu não ache que esta seja sua última palavra) que, pelo contrário, o nosso intelecto é o nosso verdadeiro eu. [...] Aristóteles viu as emoções não apenas como úteis, mas como essenciais à melhor vida que os homens podem alcançar na prática. Embora

\footnotetext{
${ }^{9}$ Ibid., p. 90 (I 131102 b28).

${ }^{10}$ Ibid., p. 551-552 (X $\left.81178 \mathrm{a} 8-15\right)$.
} 
dividido, ele reconhece que uma vida de nada mais que contemplação não é possível para nós. Até mesmo os filósofos devem comer e viver em sociedade, e a vida mais feliz envolverá também o exercício das virtudes em sociedade. As virtudes, por sua vez, envolvem acertar o ponto médio na emoção, bem como na ação ${ }^{11}$.

Assim, percebemos que Aristóteles não deixa os homens comuns fora de suas considerações sobre a vida feliz dos cidadãos, e admite inclusive que esses homens sejam a maioria. Aristóteles igualmente não retira os filósofos do convívio na pólis, pois não é o fato de serem filósofos que fará com que deixem de ser humanos e de apresentar função e necessidades específicas à humanidade. Além do mais, entende que mesmo os homens mais excelentes carecem de convívio, para deixar claras as suas aptidões e beneficiar seus amigos com sua companhia ${ }^{12}$. No convívio desses homens em comunidade é que aparecem as emoções e esse é um dos motivos do papel de destaque que têm na ética aristotélica e na sua proposta da vida feliz. Para ressaltar essa interpretação devemos continuar a examinar as propostas de Ética a Nicômaco I 13 acerca das diferentes capacidades anímicas e buscar compreender como essas tais capacidades podem estar associadas à emoção.

\section{A alma, suas capacidades e a educação das emoções}

Diante das propostas de I 13, o que podemos depreender a respeito da alma e suas capacidades? O passo, provavelmente, interessado em introduzir a discussão das virtudes, mais especificamente da virtude ética frente à felicidade humana, acaba por não trazer grandes informações sobre a alma. É possível, porém, apreender um pouco mais que a famosa e, provavelmente, popular bipartição da alma, se contarmos, na medida do possível, com o auxílio do De anima.

Ao tomar as partes ou capacidades como constituintes do princípio vivificador que é a alma, Aristóteles abre para nós uma possibilidade maior de entender a participação do sensível no inteligível, bem como do racional no não racional da alma descrita na Ética a Nicômaco. Sendo partes de uma mesma alma, não seriam totalmente desconectadas, relacionando-se de algum modo, como explica o Zingano: “A alma é uma única forma com diferentes funções"13, e tais funções são o que aqui chamamos capacidades.

\footnotetext{
${ }^{11}$ SORABJI, R. Emotions and peace of mind. Oxford : Oxford University Press, 2002, p. 190-191; tradução nossa.

${ }^{12}$ Cf. Ética a Nicômaco Livro IX.

${ }^{13}$ ZINGANO, M. Estudos de ética antiga. São Paulo: Discurso Editorial, 2007, p. 37.
} 
Quanto a esse tema, das funções que vivificam o corpo, podemos entender que alguns seres têm capacidade perceptiva e igualmente desiderativa, porque o desejo é querer, impulso e apetite. Capacidades que estão, ao menos a princípio, associadas às formas da percepção sensível e aos sentidos que lhes correspondem, que, na descrição de Aristóteles, são os mesmos que ainda conhecemos: tato, olfato, paladar, visão e audição.

Para que os viventes sejam classificados como animais, todos devem possuir ao menos um desses sentidos: o tato. Os animais que apresentam percepção sensível igualmente têm prazer e dor. Ao serem capazes de perceber o prazeroso e o doloroso também apresentam apetite, que é desejo pelo prazeroso, fogem ou buscam o que lhes aparece como prazeroso. Tais animais apresentam, obviamente, percepção do alimento pelo tato sentido por meio do paladar. Todos os seres vivos se alimentam de coisas secas e úmidas, quentes e frias percebidas pelo tocar, mas os seres vivos que possuem tato igualmente possuem desejo. Com as descrições e afirmação feitas até agora, percebemos uma espécie de hierarquia entre as capacidades. Mas, qual a razão de serem dispostas em sucessão? A resposta do filósofo é que:

[...] sem a nutritiva não existe a capacidade perceptiva, embora nas plantas a nutritiva exista separada da perceptiva. E, novamente, sem o tato, nenhum dos outros sentidos subsiste, embora o tato subsista sem os outros, pois diversos animais não têm a capacidade perceptiva, uns têm a locomotiva e outros não. Por fim, pouquíssimos têm cálculo e raciocínio. Pois, entre os seres perecíveis, naqueles em que subsiste cálculo também subsiste cada uma das outras, nem todos têm cálculo (e alguns nem sequer imaginação, ao passo que outros vivem unicamente por meio dela). $\mathrm{O}$ intelecto capaz de inquirir requer uma outra discussão. É claro, então, que o enunciado de cada uma destas capacidades é também o mais apropriado a respeito da alma ${ }^{14}$.

A relação entre as capacidades em sucessão indica o que nos permite falar de emoções educáveis graças aos seus contatos com a parte racional, sendo por isso assunto relevante à nossa pesquisa. Fazemos tal afirmação porque a capacidade perceptiva mencionada no passo mantém contato com a desiderativa e, portanto, aparece como relacionada às afecções do corpo e da alma entre as quais estão aquilo que entendemos como emoções.

Por ora, nos damos por satisfeitos em compreender e esclarecer certas questões levantadas pelo começo da Ética a Nicômaco acerca da alma e de suas capacidades, com o auxílio do De anima. A discussão sobre as partes da alma aparece mais detalhadamente neste último tratado, em uma franca discussão com os filósofos que se dedicaram anteriormente à questão, e nos indica que em Aristóteles, mesmo na Ética a Nicômaco, o que costuma ser chamado "parte" da alma parece ser capacidade daquilo que o filósofo entende por alma, sendo esta definida pelo que faculta ao corpo com o qual forma um

\footnotetext{
${ }^{14}$ ARISTÓTELES. De anima. São Paulo: Editora 34, 2012, p. 78 (II 3 414a34-415a13)
} 
todo substancialmente uno desempenhar: o exercício de suas capacidades - das mais básicas às mais complexas.

O estudo da alma e de suas capacidades nos levou à discussão da existência de uma alma composta pelas capacidades que faculta a um corpo. Mas, por que deveríamos nos deter em uma pesquisa sobre a alma em um trabalho que se pretende de cunho ético? A questão começa a ser respondida ainda por Ética a Nicômaco I 13, passo no qual Aristóteles menciona uma alma bipartida a fim de defender a existência de diferentes virtudes que comporiam a vida feliz. Entender essa proposta somente às luzes do tratado ético em questão não nos pareceu suficiente e, por isso, optamos por recorrer ao $D e$ anima, obra dedicada ao assunto. Ademais, ao longo da exposição da Ética a Nicômaco, percebemos que a interpretação de uma alma composta pelas capacidades mencionadas que podem se relacionar no composto corpo e alma contemplaria nossa interpretação das emoções, já que o filósofo estudado as propõe como "pertencentes" à capacidade desiderativa da alma capaz de participar da razão. Cremos que a única forma de acatar essa proposta seria compreender a alma como algo sem partes totalmente isoladas umas das outras. Defendemos essa interpretação a fim de que as capacidades anímicas pudessem se comunicar, de que o desiderativo participasse da razão, dando ao desiderativo a possibilidade de ser educado conforme o que manda a razão, a despeito da proposta da capacidade nutritiva acima apresentada. Esta capacidade igualmente participa da vida humana mais completa, pois não é possível a homem nenhum, nem mesmo aos filósofos, deixar de se alimentar, por exemplo, embora não interferira diretamente na vida ética. Assim, pelos contatos constatados entra as parte e capacidades da alma é que defendemos que as emoções pensadas por Aristóteles, em sua maioria ${ }^{15}$, são educáveis.

\section{Conclusão}

É possível, conforme nossa interpretação da Ética a Nicômaco, educar as emoções. Entender que as partes da alma não são isoladas totalmente umas das outras levou-nos a entender que a possibilidade de se educar as emoções existe pelo contato entre as partes racional e não racional, que é tipicamente humano. Para podermos sustentar essas propostas, iniciamos com um estudo sobre o tema das emoções, vez que Aristóteles aponta a virtude, ao menos em sua face ética, como boa medida nas emoções e nas ações.

\footnotetext{
${ }^{15}$ Todavia, o filósofo ressalta que tanto certas emoções como algumas ações são más desde a forma como
} são nomeadas. A estas é provável que não caiba moderação. 
A pesquisa conduziu nossa discussão em direção a Ética a Nicômaco I 13, que propõe a bipartição da alma e que nos apresenta as partes racional e não racional da alma, bem como a possibilidade do não racional ouvir a razão.

A partir da proposta da existência de "partes" na alma, pudemos pensar acerca de uma alma composta por diferentes capacidades operadas majoritariamente pelo corpo. Tal entendimento foi possível justamente devido ao conjunto das capacidades indicadas pelo De anima e pela Ética a Nicômaco como típico à alma do homem, a saber, nutritiva, perceptiva (e com esta, a desiderativa) e raciocinativa. Por esse motivo, julgamos pertinente desenvolver, mas apenas de modo a sanar nossas dúvidas acerca da educabilidade das emoções, um pequeno estudo a respeito da alma humana.

A defesa de uma alma composta por capacidades imprescindivelmente correlacionadas e que têm suas funções manifestas, mesmo que imperceptivelmente, no corpo nos permitiu tratar as emoções como afecções do conjunto corpo/alma. Tudo isso só foi possível porque pensamos numa teoria que entendeu a capacidade desiderativa como um todo. O desejo apresenta diferentes tipos de manifestação relacionados aos seus objetos e às relações dos tipos de desejo com a razão ${ }^{16}$. Sendo da alçada do desiderativo, as emoções, como os desejos aos quais se relacionam, podem sofrer algum tipo de educação, validando, desde o início de nossa pesquisa, a teoria sobre a possibilidade de mudar as emoções favoravelmente à vida ética conforme a razão.

\section{Referências}

AGGIO, J. O. Prazer e desejo em Aristóteles. Salvador: Edufba, 2017.

ANTISSERI, D.; REALE, G. História da filosofia. Vol. 1. São Paulo: Paulus, 2003.

ARISTÓTELES. The Complete Works. Princenton: Princenton University Press, 1995. . De anima. São Paulo: Editora 34, 2012. . Éthique à Nichomaque. Tradução de Julien Tricot. Paris : Vrin, 2012. .Ética a Nicómaco. Edición bilingüe y traducción de María Arujo y Julian Marías. Madrid : Centro de Estudios Político y Constitucionale, 2009. . A Política. São Paulo: Martins Fontes, 2006.

\footnotetext{
${ }^{16}$ Proposta devedora aos estudos de Aggio (2017) dedicados à questão do desejo e do prazer na Ética a Nicômaco.
} 
KENNY, A. Uma nova história da filosofia. Vol. 1. São Paulo: Loyola, 2011.

SANTOS, R. A. Sobre a doutrina das paixões no estoicismo. 2008. 100f. Tese (Doutorado em Filosofia) - UNICAMP, Campinas, 2008. Disponível em:

http://repositorio.unicamp.br/bitstream/REPOSIP/280135/1/Santos_RonildoAlvesdos D.pdf. Acesso em 20 de nov. de 2019.

SORABJI, R. Emotions and peace of mind. Oxford : Oxford University Press, 2002.

ZINGANO, M. Estudos de ética antiga. São Paulo: Discurso Editorial, 2007. 